Published in final edited form as:

Soc Sci Med. 2018 November ; 217: 84-91. doi:10.1016/j.socscimed.2018.09.062.

\title{
Long-Term Effects of Disaster on Depressive Symptoms: Type of Exposure Matters
}

\author{
Maureen Wilson-Genderson, Ph.D. ${ }^{1}$, Allison R. Heid, Ph.D. ${ }^{2}$, Rachel Pruchno, Ph.D2, \\ ${ }^{1}$ Temple University School of Public Health, Philadelphia, Pennsylvania \\ ${ }^{2}$ New Jersey Institute for Successful Aging, Rowan University School of Osteopathic Medicine, \\ Stratford, New Jersey
}

\begin{abstract}
Rationale: Natural disasters have the potential to change the lives of older people, yet most studies rely on small convenience samples, few include assessments of people prior to the disaster, and only a handful examine the effects of different types of exposure.
\end{abstract}

Objective: Our analyses add new knowledge to the literature by examining the ways in which four types of exposure (i.e., geographic, peri-traumatic stress, personal and property loss, and poststorm hardship) affect depressive symptoms experienced by older people over a five-year period.

Method: We analyzed four waves of data from the ORANJ BOWL panel using multilevel mixed effects models.

Results: We found that although each type of exposure had an independent effect on depressive symptoms, the effects of peri-traumatic stress were dominant.

Conclusions: As nearly $20 \%$ of people in the United States will experience a natural disaster during the course of their lives, it is critical to understand how disaster exposure can influence mental health because each type of exposure demands a different response. Finding that an individual's emotional response during the disaster plays an important role in the development of depressive symptoms suggests that reduction of exposure to traumatic stress during a storm (i.e., evacuation from a storm area) is important for older people. Likewise, immediate interventions following a disaster that target people experiencing high levels of peri-traumatic distress may be particularly effective and that failing to attend to these people may miss a critical opportunity and result in years of suffering.

\section{Keywords}

Disaster; depressive symptoms; older people; Hurricane Sandy; New Jersey

"Corresponding author Rachel A. Pruchno, Ph.D., New Jersey Institute for Successful Aging, Rowan University-SOM, 42 E. Laurel Rd., Suite 2300, Stratford, NJ 08084, pruchnra@ rowan.edu, 856-566-6822.

Ethical Approval

Ethical approval for this study was granted by the Rowan University IRB.

Publisher's Disclaimer: This is a PDF file of an unedited manuscript that has been accepted for publication. As a service to our customers we are providing this early version of the manuscript. The manuscript will undergo copyediting, typesetting, and review of the resulting proof before it is published in its final citable form. Please note that during the production process errors may be discovered which could affect the content, and all legal disclaimers that apply to the journal pertain. 


\section{Introduction}

On October 29, 2012, Hurricane Sandy, the largest Atlantic hurricane on record, struck the Eastern United States, killing 117 people and injuring countless others (CDC, 2013). More than three-quarters of a million people were forced to leave their homes (IDMC, 2012); numerous others had homes damaged by the storm. Over eight million people were without power for weeks, a situation exacerbated by an unseasonably early snowstorm and frigid temperatures that followed the hurricane (U.S. Department of Commerce, 2013). Hurricane Sandy resulted in $\$ 65$ billion dollars in damages (HRD, 2014). In New Jersey, Hurricane Sandy had a particularly deleterious effect on older people. Kim et al. (2017) report that allcause mortality rates of people aged 76 and older increased $10 \%$ in the month following the hurricane, with mortality rates particularly high in communities severely affected by the storm. Assisted living facilities reported a surge in applications (Eltman, 2013). Among those exposed to Hurricane Sandy were several thousand community-dwelling older New Jersey residents recruited in 2006 to an ongoing longitudinal panel. As such, Hurricane Sandy, while tragic, presented a unique opportunity to understand the impact of disaster on older people.

Disasters are traumatic events that simultaneously alter the lives of many people. As acute events, disasters can trigger a series of subsequent stressful events including death or injury of a family member, loss of housing, and loss of employment (Forbes et al., 2015; Galea et al., 2005; Guha-Sapir et al., 2015; Lock et al., 2012). Disasters can be caused by a natural event such as an earthquake, hurricane, or tornado; they can be human-made, triggered by a terrorist act; or disasters can result from a combination of technology failure and operator error such as an airplane or train crash. Although some research suggests that human-made disasters are more harmful to mental health than natural disasters (Galea et al., 2005), this conclusion may be premature, as it is more difficult to identify victims of natural disasters. Most studies of natural disasters rely on small convenience samples, and few studies include assessments of people prior to the disaster. The analyses that follow add new knowledge to the literature regarding the effects that natural disasters have on the mental health of older people by examining how four different types of exposure (i.e., geographic, peri-traumatic stress, personal and property loss, and post-storm hardship) affect depressive symptoms over a five-year period.

\section{Disasters and Depression}

Research consistently finds an association between disasters and post-traumatic stress disorder (PTSD), with people experiencing higher levels of exposure having a greater likelihood of PTSD (Andrews et al., 2007; Brewin et al., 2000; Galea et al., 2005; Neria et al., 2008; Utzon-Frank et al., 2014). However, studies examining the association between disasters and depression or depressive symptoms yield inconsistent findings. A metaanalysis by Tang, Liu, Xue, and Zhang (2014) revealed that prevalence of depression ranged from $5.8 \%$ to $54.0 \%$ in adults exposed to natural disasters. Generalizability of findings is limited because many of the variables included in the meta-analysis were included in a small proportion of the studies, most of the disasters studied were earthquakes, and most studies 
relied on retrospective reports. Additionally, all studies were cross-sectional, and the time between the disaster and assessment ranged from one month to four years. Finally, because most disaster studies do not include information assessed prior to the disaster, it is difficult to know whether people who are depressed after a disaster became depressed as a result of the disaster or were already depressed prior to the disaster. One of the few longitudinal studies of disaster that controlled for personal circumstances, prior mental health, and childhood family background revealed that people with high levels of exposure to the Christchurch, New Zealand earthquakes had higher rates of mental disorder than people not exposed (Fergusson, Horwood, Boden, \& Mulder, 2014). The extent to which these findings can be generalized to older people, however, is limited because the study relied on a cohort of people who were 35 years old when the disaster struck.

\section{Differential Definitions of Exposure and Depression}

Inconsistent findings regarding the effects that disasters have on depressive symptoms may be a function of the different ways that researchers have operationalized exposure to disaster. Some scholars have defined exposure as a function of geographic location (Boscarino et al., 2013; Bryant et al., 2014; Gruebner et al., 2015; Schwartz et al., 2016). Others focus on personal and property damage (Galea et al., 2007; Lowe et al., 2015; Schwartz et al., 2017; Tsuboya et al., 2016). Still others define disaster exposure as peri-traumatic stress (Bell et al., 2017; Schwartz et al., 2016; Tang et al., 2014), and others focus on post-disaster hardship (Armenian et al., 2002; Forbes et al., 2015; Lock et al., 2012; Schwartz et al., 2016; Tang et al., 2014). However, because few studies have included more than one measure of exposure, it is difficult to know what it is about disaster exposure that is most stressful (Lieberman-Cribbin et al., 2017).

Studies defining exposure as a function of geography find evidence that increases in mental health disorders are clustered in locations where people are more exposed to the disaster (Boscarino et al., 2013; Bryant et al., 2014; Gruebner et al., 2015; Schwartz et al., 2016).

The effects that personal and property loss following disaster have on mental health are less clear. Some research found that property exposure (e.g., home damaged or destroyed, vehicle loss) and personal exposure (e.g., family member injured, separation from family, evacuated) were associated with higher levels of distress, but not with anxiety or depression. A follow-up study by Schwartz et al. (2017) three to four years after the disaster revealed that property damage but not personal damage was positively associated with distress. Similarly, Tsuboya et al. (2016) found that after adjusting for demographics and pre-disaster mental health, people living in homes destroyed by the 2011 East Japan Earthquake had significantly elevated depressive symptoms three years later. Interestingly, this study found that people who lost family or friends in the earthquake did not have higher depressive symptoms three years after the disaster. Other research found that neither disaster-related trauma (e.g., self-injury, injury of family/friend, death), nor disaster-related stressors (e.g., home displacement, loss of utilities, home damage, income decline) were associated with depression (Lowe et al., 2015). Some research finds that the effects of property loss are less important than the effects of physical illness, injury, and physical adversity (Galea et al., 2007). 
Peri-traumatic experiences, the emotional responses experienced in the moment of the disaster, have been under-recognized as risk factors for depression. In their meta-analysis, Tang et al. (2014) report that people who experienced fear during natural disasters were more likely to suffer from depression after a disaster than people who did not experience fear. More recent work has confirmed this finding indicating that peri-trauma is associated with higher levels of perceived stress (Schwartz et al., 2016) and with an increased risk of depression following earthquake exposure (Bell et al., 2017).

Finally, research suggests that post-disaster experiences can affect disaster recovery (Bleich et al., 2006; Hobfoll, 2001). Empirical studies have highlighted the critical role played by a complex series of stressful events including death, disrupted living arrangements, and financial or job loss that can follow a disaster (Armenian et al., 2002; Forbes et al., 2015; Lock et al., 2012). Tang et al.'s (2014) meta-analysis revealed that people who experienced unemployment following a disaster experienced higher levels of depressive symptoms than people who did not experience unemployment. More recently, Schwartz et al. (2016) found that people suffering financial loss following Hurricane Sandy had higher perceived stress scores than people not experiencing financial loss.

In sum, it is not clear what it is about disaster exposure that is associated with depression because many studies include only a single indicator of exposure and studies that have included multiple exposure measures typically create unique composite measures that render findings difficult to compare (Lowe et al., 2015; Schwartz et al., 2017). The few studies that have measured and used distinct indicators of exposure reveal different results. LiebermanCribben et al. (2017), for example, found significant discrepancies between self-reported flood exposure and FEMA flood exposure reports, with self-reported flood exposure but not FEMA reports being a predictor of mental health outcomes. Using multilevel modeling, Lowe et al. (2015) examined individual and community-level factors associated with posttraumatic stress. They found that people who experienced more disaster-related stressors and those living in communities with a lower percentage of people living alone experienced higher levels of post-traumatic stress. A subsequent study by this team found that disasterrelated stressors were more strongly associated with post-traumatic stress for people living in communities with high unemployment (Lowe et al., 2016). A study that included measures of peri-trauma and post-disaster distress among people exposed to earthquakes in New Zealand found that while both peri-traumatic stress and disruption distress were associated with depression; the dominant predictor of depression was peri-traumatic stress (Bell et al., 2017).

\section{Long-term Effects of Disaster Exposure on Depression}

Beyond a lack of understanding of the differential impact of exposure type on depression, another limitation of current work is that, because most disaster studies rely on crosssectional designs and convenience samples, the long-term effects of disaster remain unknown. Some longitudinal studies find that symptoms and prevalence of psychiatric conditions peak within a year of disaster and then improve over time (Neria et al., 2008; Norris et al., 2002). However, there is evidence that disasters can have long-term consequences (i.e., over one year; Abramson et al., 2008; Kessler et al., 2008; Rhodes et al., 
2010; Schwartz et al., 2016). For example, Schwartz and colleagues (2017), using multivariate analysis, revealed that the main driver of stress three to four years after Hurricane Sandy was damage to property and not personal factors, such as separation from family. The authors interpret these findings by suggesting that by the time they interviewed their participants issues regarding separation from family had already been resolved.

Green, Lowe, and Rhodes' (2012) analysis demonstrates the contributions that multiwave research designs make to understanding disaster effects. In one of the few disaster studies to contrast findings based on post-disaster only, pre-and post-data, and pre- and multiple postwaves of data, Green et al. (2012) reported that post-disaster cross-sectional estimates of the impact of traumatic stress exposure and post-disaster social support on post-disaster psychological distress were somewhat inflated, but that general trends persisted when controlling for pre-disaster data. Meanwhile, hierarchical linear modeling of three waves of data revealed that lower pre-disaster social support was associated with higher psychological distress at the time of the disaster and that higher traumatic stress exposure was associated with increases in psychological distress after the storm. Similarly, in a review article, Pietrzak et al. (2012) found that patterns of decline in symptoms and prevalence of disorder had greater variability in studies that included three or more assessments. Some studies found simple linear decline (Steinglass et al., 1990), some found initial decline followed by stabilization (Thompson et al., 1993), while still other studies found evidence of a quadratic trend (Phifer et al., 1989). These studies confirm the importance of longitudinal designs for documenting the enduring effects that disasters can have.

Yet even longitudinal studies leave doubt about the effects that disasters have on mental health because they rarely include data collected prior to the disaster (i.e., $4.4 \%$ of disaster studies; Norris et al., 2002). Recent longitudinal studies perpetuate this problem, as they do not include data collected prior to the disaster (Bell et al., 2017; Bryant et al., 2014; Lowe et al., 2015; Schwartz et al., 2017). Without pre-disaster information there is danger of attributing preexisting differences in mental health to the disaster itself (Green et al, 2012).

\section{Current Study}

Little is understood about how older people fare in the face of disaster. It may be that older people, because of their lived experiences, are more resilient in the face of a disaster. In fact, Schwartz et al. (2016) found that older people were less likely to report distress following a hurricane and Bonanno, Galea, Bucciarelli, and Vlahov (2007) found that people aged 65 and older were three times as likely to be resilient in the aftermath of the September 11 attacks as people between the ages of 18 and 24. On the other hand, it may be that older people, especially those with chronic illnesses and few resources, are more vulnerable in the face of disaster (Heid et al., 2016). However, because few disaster studies have included older people (only one of the 31 studies included in Tang et al.'s 2014 meta-analysis included people aged 60 and older), the effects that disasters have on older people remains unknown.

The analyses that follow are unique because they include pre-disaster assessments, focus on people living in New Jersey aged 56 to 80 when Hurricane Sandy struck, and examine how 
differential types of exposure to the hurricane (i.e., geography, peri-traumatic stress, personal and property loss, post-storm hardship) impact depressive symptoms over five years. We test the following hypotheses:

1. Older people living in counties hardest hit by Hurricane Sandy will have higher levels of depressive symptoms than older people not living in these counties.

2. Older people who experience higher levels of peri-traumatic stress during Hurricane Sandy will experience higher levels of depressive symptoms five years later than older people who experience lower levels of peri-traumatic stress.

3. Older people experiencing higher levels of personal and property loss following Hurricane Sandy will experience higher levels of depressive symptoms five years later than older people experiencing lower levels of personal and property loss.

4. Older people experiencing higher levels of post-storm hardship will experience higher levels of depressive symptoms five years after the storm than older people experiencing lower levels of post-storm hardship.

After testing the effect of each type of exposure individually, we examine, in an exploratory fashion, the relative contributions that peri-traumatic stress, geographic location, personal and property loss following Hurricane Sandy, and post-storm hardship have on depressive symptoms.

Analyses control for age, gender, socio-economic status (education and income), and preexisting mental health problems, as previous studies find these characteristics associated with depressive symptoms (Adeola, 2009; Bonanno et al., 2007; Boscarino et al., 2014; Breslau et al., 1998; Caramanica et al., 2015; Galea et al., 2007; Hamama-Raz et al., 2015; Kessler et al., 1995; Lowe et al., 2015; Picou et al., 2010; Schwartz et al., 2016; Schwartz et al., 2017; Tolin et al., 2006).

\section{Method}

\section{Participants}

Between 2006 and 2008, we recruited and completed baseline (Wave 1) telephone interviews with 5,688 people who were part of the ORANJ BOWL panel. The goal of ORANJ BOWL is to identify factors that influence successful aging. We recruited participants using cold calling and list-assisted random-digit-dialing (RDD) procedures. Eligible participants were between the ages of 50 and 74, living in New Jersey, and able to participate in a one-hour, English-language telephone interview. Coverage loss due to cell phone-only households was small due to sample demographics (Blumberg et al., 2007). ORANJ BOWL achieved a response rate of 58.73\%, using standard American Association for Public Opinion Research calculations, and a Cooperation Rate of $72.88 \%$, consistent with or better than average RDD response rates. We provide details regarding sample development in Pruchno, Wilson-Genderson, Rose, et al. (2010). Participants were representative of older adults (aged 50-74) living in New Jersey in 2006, except for a slightly higher rate of women and individuals with more years of education. Table 1 includes 
sample descriptive statistics. ORANJ BOWL participants lived in 1,644 of New Jersey's 1,912 census tracts.

One year after their baseline interview, a subsample of participants was re-contacted and asked to complete a personality measure (Wave 2). We excluded data from this wave in our analyses because we did not collect information about depressive symptoms at that wave.

In 2011, we mailed a questionnaire (Wave 3) to all ORANJ BOWL respondents (see Figure 1 for sample flow). Compared to those who died, withdrew, or did not complete the Wave 3 questionnaire, people completing the questionnaire $(N=3,387)$ had more years of education $(F=47.85, d f=3 ; 5,671)$ and were wealthier $(F=54.16, d f=3 ; 5,018)$. Completers were also older than non-completers but younger than those who withdrew or died $(F=47.26, d f$ $=3 ; 5,684)$. Completers were more likely to be women than those who died $\left(X^{2}=21.36, d f\right.$ $=3, N=5,688)$ and less likely to be African American than those who died or did not complete Wave $3\left(X^{2}=97.48, d f=3, N=5,688\right)$.

In 2014, approximately 18 months after Hurricane Sandy struck, we mailed a questionnaire (Wave 4) to all ORANJ BOWL respondents known to be alive at Wave 3. We called participants who did not complete the interview and whenever possible, we completed the interview by telephone. Compared to those who had died, withdrawn, or did not complete the Wave 4 questionnaire, people completing the Wave 4 questionnaire $(N=3,609)$ reported more years of education $(F=64.12, d f=3 ; 5,671)$ and higher income $(F=99.93, d f=3$; $5,018)$. Completers were older than non-completers but younger than those who withdrew or died since Wave $1(F=89.56, d f=3 ; 5,684)$. Completers were more likely to be female than those who died ( $\left.X^{2}=14.67, d f=3, N=5,688\right)$ and less likely to be African American than non-completers and those who died $\left(X^{2}=103.23, d f=3, N=5,688\right)$. The availability of additional funds for sample follow-up at Wave 4 resulted in a larger sample at Wave 4 than Wave 3.

Wave 5 was completed approximately 18-months after completion of Wave 4 (2015 to 2017). Completers $(N=3,076)$ reported higher levels of education $(F=116.38, d f=3$; $5,671)$ and income $(F=148.30, d f=3 ; 5,018)$ than those who had died, withdrew, or did not complete Wave 5. Completers were significantly older than non-completers and younger than those that withdrew or died $(F=120.45, d f=3 ; 5,684)$. Completers were more likely to be female than those who died $\left(X^{2}=15.06, d f=3, N=5,688\right)$ and less likely to be African American than those who died, withdrew, or did not complete Wave $5\left(X^{2}=146.15, d f=3\right.$, $N=5,688)$.

\section{Measures}

We assessed peri-traumatic stress at Wave 4 by asking participants to report whether they felt: 1) in immediate physical danger during Hurricane Sandy, and 2) distressed or fearful during Hurricane Sandy. Bell et al. (2017) asked similar questions. Responses to each question were recorded on a three-point scale: 0 (no), 1 (a little), or 2 (a lot). We summed responses to these two questions to create a peri-traumatic stress score. The sample mean was $0.86(S D=1.0)$ with a range of $0-4$. 
We measured personal and property loss at Wave 4 by asking participants if they experienced: 1) physical injury, 2) a need for medical attention, 3) any home damage, 4) family or close friends injured or killed, 5) loss of utilities, and/or 6) damage to a personal automobile as a result of Hurricane Sandy. Consistent with the approach used by scholars of life events (Dowd et al., 2014; Jayawickreme et al., 2017; Slopen et al., 2011) and disasters (Fergusson et al., 2014; Galea et al., 2007; Lieberman-Cribbin et al., 2017; Schwartz et al., 2017), responses were summed. As only six people experienced four or more of these stressors, we capped this variable at three, yielding a range of $0-3$.

We assessed post-storm hardship at Wave 5 by asking participants if, because of Hurricane Sandy, they had: 1) stopped working, 2) left their home, 3) had mold problems at home, and/or 4) lost income. Lowe et al. (2015) asked similar questions. As with personal and property loss, we summed responses. We capped this variable at two because only four people experienced three of these stressors, yielding a range of $0-2$.

We defined geographic exposure as living in one of the nine counties identified by FEMA (2018) as hardest hit by Hurricane Sandy. These included: Atlantic, Bergen, Cape May, Essex, Hudson, Middlesex, Monmouth, Ocean, and Union counties. Brilleman et al. (2017) also operationalized geographic exposure based on FEMA classifications. Living in a stormexposed area was denoted ' 1 '; not being in the defined area was coded ' 0 '; 3,216 (56.5\%) of participants were living in a county affected by the storm.

We measured depressive symptoms at each wave using the 10-item short form of the Center for Epidemiologic Studies Depression Scale (CES-D; Andresen, Malmgren, Carter, \& Patrick, 1994). Each item was scored from 0 (none of the time) to 3 (most of the time). Two items ("I felt hopeful about the future" and "I was happy") were reverse coded. Total scores ranged from 0 to 30; Cronbach's alpha $=.82$. Higher scores indicated more depressive symptoms.

At baseline, participants indicated whether a physician had ever told them they had depression, anxiety, or another emotional problem. Responses were coded as 0 (no) or 1 (yes). A quarter of the sample reported having had a lifetime diagnosis of depression ( $n=$ 1,357).

At baseline, respondents reported their age, gender $(0=$ male, $1=$ female), income (range from $1=$ less than $\$ 15,000$ to $6=$ more than $\$ 150,000$ ), educational attainment (range from $1=$ less than high school to $9=$ doctoral degree $)$ and race $(0=$ not African American, $1=$ African American).

\section{Statistical Analysis}

First, we examined sample descriptive information for each wave of data collection on demographic characteristics, lifetime diagnosis of depression, storm exposure, and depressive symptoms. We computed bivariate correlations for the storm exposure variables. Next, we ran multilevel mixed effects models that account for the nesting of observations within participants and permit the inclusion of neighborhood characteristics at Level 2 of the model. These analyses examine the association between exposure to Hurricane Sandy and 
depressive symptoms using all available waves of data for each participant and unbiased estimates for missing data. Previous analyses revealed that at the third wave of data collection, which coincided with the 2008 Economic Recession, our sample evidenced elevated CESD scores that subsequently attenuated (Pruchno, Heid, \& Wilson-Genderson, 2016. As such, we examined whether treating Wave 3 as baseline and controlling for Wave 1 CESD or treating Wave 1 as baseline and dropping Wave 3 (to remove the effect of the 2008 Economic Recession) affected interpretation of CESD slopes. These two approaches yielded results identical to the models reported here. Following Singer and Willett (Singer et al., 2003), we report findings based on all waves of data.

Participants included in the multilevel models participated in the baseline interview and at least one interview after the storm. After confirming a substantial within person ICC of .57 over time, we created a within-person unconditional model $\left(Y_{i t}=\pi_{0 i}+\pi_{1 i}\left(\right.\right.$ wave $\left._{i t}\right)+\pi_{2 i}$ $\left(\operatorname{lag}_{i t} t+e_{i t}\right)$ to estimate average linear and person-specific change over time in depressive symptoms. In this model, $Y_{i t}$ is the CES-D score at time $t$ for participant $i_{O_{i}}$ is initial status of CES-D for participant $i$. The linear time parameter $\pi_{1 i}$ was coded as 1, 3, 4, 5 (wave) and represents the point of measurement for the linear change in depressive symptoms. A lag variable was included to capture the exact amount of time that had passed for each individual participant since baseline ( $\left(a g_{i t}\right) ; e_{i t}$ is the error for participant $i$ at time $t$.

Once the form of the change and average slopes were determined, we introduced additional variables as follows: Model B added demographic characteristics (age, gender, income, and education) and prior lifetime diagnosed depression to account for associations between person-level characteristics and depressive symptoms. Initial model evaluation found that race and marital status were not significantly associated with depressive symptoms; hence, we excluded these variables from subsequent models. Models C-1 through C-3 added one of the individual-level exposure variables (peri-traumatic stress, personal/property loss, poststorm hardship) at Level 1 and the geographic indicator of exposure at Level 2. Model D simultaneously included all three individual-level exposure variables at Level 1 and the geographic indicator at Level 2.

Model results are presented as regression parameter estimates $(\beta)$ with the associated standard errors reflecting the strength of the association of each variable and change in depressive symptoms (see $Y_{i t}$ above), ) and the significance test assessed as $p$-values less than .05. Fit indices are presented for the sake of model comparison including $-2 \mathrm{Log}$ Likelihood, AIC, AICC, BIC and $\chi$, all of which are interpreted as smaller is better. To assess the robustness of the models given missing data on income, we tested the models in the following three ways: (1) using data from participants who had complete data, (2) using SAS Proc MI for multiple imputation, and (3) removing the income variable from the model. The model results were similar and the parameter interpretations were the same under all three conditions. In order to account for risk of death throughout the study period, sensitivity analyses were conducted following procedures described by Berry, Ngo, Samelson, and Kiel (2010). Although people who died were more depressed than those who did not die, death status did not affect other findings and as a result, death status was not included in the models in favor of parsimony. SAS 9.4 was used for all analyses. 


\section{Results}

Table 1 presents descriptive statistics for the sample at each wave of data collection. Table 2 shows bivariate correlations amongst the disaster exposure variables for people living in and out of counties identified by FEMA as affected by Hurricane Sandy.

The initial multi-level model (Model A; see Table 3) revealed a significant linear increase in depressive symptoms over time (Wave) as well as an additional significant increase over time attributable to how much time had passed for the individual participant (Lag). Model B revealed that age, education, and income were all significantly negatively associated with depressive symptoms and that lifetime diagnosis of depression was positively associated with depressive symptoms. Younger people, those with less education, and those with lower income reported significantly greater depressive symptoms. The linear effect of time (Wave) remained positively associated with depressive symptoms but lag was no longer significant. This indicates that the exact amount of time passed neither amplified nor dampened the linear increase in depressive symptoms over time.

Model C-1 revealed that all the previously tested parameters remained the same as in Model $\mathrm{B}$ and that peri-traumatic stress at the individual level was significantly associated with depressive symptoms, with those experiencing more peri-traumatic stress reporting higher levels of depressive symptoms over time. Living in a county identified by FEMA as storm affected was not associated with depressive symptoms.

Model C-2 revealed that all the previously tested parameters remained the same as in Model $\mathrm{B}$ and that personal and property loss at the individual level was significantly associated with depressive symptoms, more personal/property damage was associated with more depressive symptoms. In this model, living in a FEMA-defined storm damaged county (Level 2) was also associated with higher levels of depressive symptoms.

Model C-3 revealed that all the previously tested parameters remained the same as in Model $\mathrm{B}$ and that experiencing post-storm hardship (at the individual level) was significantly associated with depressive symptoms, with more stressors associated with more depressive symptoms. Here too, living in a FEMA-defined storm damaged county (Level 2) was associated with higher levels of depressive symptoms.

Fit indices comparing Model C-1, C-2, and C-3 to Model B suggested an improvement in fit for each model (see Table 3). Finally, Model D, which included all forms of exposure, revealed that all the previously tested parameters remained the same as in Model B and that peritraumatic stress at the individual level was significantly positively associated with depressive symptoms. Personal and property loss, post-storm hardship (Level 1 variables), and living in a FEMA-defined storm damaged county (Level 2) were not associated with depressive symptoms. Thus, when accounting for all four types of exposure in one model, higher levels of peritraumatic stress best explained increases in depressive symptoms. Fit indices comparing Model D to Model B suggested an improvement in fit, however the fit indices were similar to that of model C-1 (peri-traumatic stress). 


\section{Discussion}

Nearly $20 \%$ of people in the United States will experience a natural disaster during the course of their lives (Kessler et al., 1995). Disasters can have devastating impacts because of the acute, life-threatening incidents in the moment of the disaster, the personal and property losses ensuing within hours or days of the disaster, and the longer-term consequences of the disaster. These effects typically occur within a given geographic region. It is critical to understand the ways that disaster exposure can influence mental health because each type of exposure demands a different response. Our analyses examined the ways in which four different types of disaster exposure affect the depressive symptoms experienced by community-dwelling older people over a five-year period. Results revealed that, accounting for geographic exposure (living in one of the nine counties hardest hit by the storm), peritraumatic stress, personal and property loss, and post-disaster hardship as a result of Hurricane Sandy each had a positive association with depressive symptoms. However, when all indicators of disaster exposure were included in the model simultaneously, the sole predictor of depressive symptoms was peri-traumatic stress. These results carry implications for future research and practice.

Peri-traumatic stress is a known risk factor for PTSD (Andrews et al., 2007; Brewin et al., 2000; Galea et al., 2005; Neria et al., 2008; Utzon-Frank et al., 2014). Findings reported here demonstrate it may also be the case for depression. We found that an individual's emotional response during the disaster plays an important role in depressive symptoms as long as five years after a disaster. This result mirrors findings reported by Bell et al. (2017) who studied survivors of the New Zealand earthquakes and found that peri-trauma had a direct influence on depression. Together, these findings of survivors of earthquakes and a hurricane suggest the critical role played by peri-traumatic stress experienced during a natural disaster on depression experienced years later. Reduction of exposure to traumatic stress during a storm (i.e., evacuation from a storm area) may decrease depressive symptoms experienced after a storm. Likewise, intervention responses following a disaster that target individuals experiencing high levels of peri-traumatic distress may be particularly effective. Failing to attend to people experiencing peri-traumatic distress may miss a critical opportunity and result in years of suffering.

Other studies find that personal and property damages following a disaster have inconsistent associations with psychological well-being (Galea et al., 2007; Lowe et al., 2015; Schwartz et al., 2017; Schwartz et al., 2016; Tsuboya et al., 2016). Our data show that when investigated independently, personal and property damages are associated with depressive symptoms, but when modeled along with peri-traumatic stress, the independent effects weaken. Findings differ from those reported by Tsuboya et al. (2016). Their study of exposure to the 2011 East Japan Earthquake revealed that after adjusting for demographics and baseline mental health, older people with homes destroyed by the earthquake, had significantly elevated depressive symptoms scores three years later. Differences in findings could be due to cultural differences, the lack of a measure of peri-traumatic stress in the earlier study, differences in the number of people in our study and Tsuboya et al.'s (2016) study who experienced home destruction, or differences in the experiences people have as a function of the nature of the disaster itself. Similarly, we found that when the independent 
effect of post-disaster hardship was examined, hardship was positively associated with depressive symptoms, confirming Tang et al.'s (2014) finding regarding unemployment and Schwartz et al.'s (2016) finding regarding financial loss. However, when modeled along with peri-traumatic stress, the effects of post-disaster hardship also subsided. Thus, although personal and property damages and post-disaster hardship can serve as challenges for individuals, findings from our study reveal that the implications for depression are less than that attributed to emotional experiences during a storm.

Our study sheds light on the way in which geographic exposure affects depressive symptoms, as well. While others report increases in mental health problems in locations where people are more exposed to a disaster (Boscarino et al., 2013; Bryant et al., 2014; Caramanica et al., 2015; Gruebner et al., 2015; Schwartz et al., 2016), we find a more subtle association between geographic exposure and depressive symptoms. When modeled with peri-traumatic stress, geography was not significant, but when modeled with personal and property loss and post-disaster hardship, geography added significantly to predicting depressive symptoms. This finding is most likely a function of the strength of peri-traumatic stress in relationship to the other indicators of exposure.

\section{Limitations}

A strength of our study is its use of a large, representative sample of people who had differential types of exposure to Hurricane Sandy, its longitudinal design that included assessments of people before and after Hurricane Sandy, and its analytic approach that modeled exposures at both the level of the individual and the county. Like all studies, however, this one had its limitations. Indicators of peri-traumatic stress, personal and property loss, and post-disaster hardship were self-reported between 12 and 53 months after the Hurricane. As such, our study is subject to a retrospective recall bias. Second, our measure of peri-traumatic stress included only two items. Because our analyses found that even this crude indicator had a powerful effect on depressive symptoms, future studies should include more sophisticated measures such as the Peritraumatic Behavior Questionnaire (Agorastos et al., 2013) or the Peritraumatic Distress Scale (Brunet et al., 2000). Third, our decision to sum responses of personal/property losses and for post-storm hardship, predicated by the small number of people experiencing each stressor, does not enable us to test how each individual type of loss affected depressive symptoms. As is true in life events research (Dowd et al., 2014; Jayawickreme et al., 2017; Slpen et al., 2011) and other disaster studies (Fergusson et al., 2014; Galea et al., 2007; Lieberman-Cribbin, et al., 2017; Schwartz et al., 2017), such summative measures provide a crude proxy of stressful experiences. Fourth, our indicator of geographic exposure was at the level of the county, which is a very rough indicator of exposure. Future studies should incorporate more nuanced measures of geographic exposure, such as flooding levels and community damage. Fifth, while this study examined the correlations among disaster constructs and the independent predictability of each in the presence of the others, it did not consider how different types of exposure might be related to each other mechanistically. Future work should consider how one type of exposure might increase or decrease the likelihood of experiencing another and if such compound associations further contribute to negative mental health outcomes. Finally, study attrition over time resulted in an underrepresentation of people with lower 
education, lower income, and/or of minority status. Moreover, people who withdrew from the study or those who died were older and frailer than people remaining in the study. It is also likely that people who did not participate in the post-Sandy interviews suffered more disaster damage and more depressive symptoms than people who continued to participate. As such, generalizability of study findings is limited and it is likely that our analyses underestimate the effects that exposure has on depressive symptoms.

\section{Conclusions}

Findings from our study add important information to our understanding of how differential forms of disaster exposure influence the mental health of older people. The way in which exposure is operationalized matters for the conclusions drawn. Moreover, the central role played by peri-traumatic stress highlights the importance of developing interventions for people who report feeling emotionally affected by a storm immediately after a disaster strikes. Funding

\section{Acknowledgments}

Funding was provided by The UMDNJ-SOM, The UMDNJ Foundation, Assistant Secretary for Preparedness and Response (1 HITEP130008-01-00), the Rockefeller Foundation (2012_RLC 304; PI: George Bonanno), and the NIA (R01 AG046463).

\section{References}

Abramson D, Stehling-Ariza T, Garfield R, et al. (2008). Prevalence and predictors of mental health distress post-Katrina: Findings from the Gulf Coast Child and Family Health Study. Disaster Med Public Health Prep, 2(2), 77-86. doi:10.1097/DMP.0b013e318173a8e7 [PubMed: 18520693]

Adeola FO (2009). Mental health and psychological stress distress sequelae of Katrina: An empirical study of survivors. Hum Ecol Rev, 6(null), 195.

Agorastos A, Nash WP, Nunnink S, et al. (2013). The Peritraumatic Behavior Questionnaire: development and initial validation of a new measure for combat-related peritraumatic reactions. BMC Psychiatry, 13(1), 9. doi:10.1186/1471-244X-13-9 [PubMed: 23289606]

Andresen EM, Malmgren JA, Carter WB, et al. (1994). Screening for depression in well older adults: evaluation of a short form of the CES-D (Center for Epidemiologic Studies Depression Scale). American Journal of Preventive Medicine, 10(1), 77-84. [PubMed: 8037935]

Andrews B, Brewin CR, Philpott R, et al. (2007). Delayed-onset posttraumatic stress disorder: A systematic review of the evidence. American Journal of Psychiatry, 164(9), 1319-1326. doi: 10.1176/appi.ajp.2007.06091491 [PubMed: 17728415]

Armenian HK, Morikawa M, Melkonian AK, et al. (2002). Risk factors for depression in the survivors of the 1988 earthquake in Armenia. Journal of Urban Health : Bulletin of the New York Academy of Medicine, 79(3), 373-382. doi:10.1093/jurban/79.3.373 [PubMed: 12200506]

Bell CJ, Boden JM, Horwood LJ, et al. (2017). The role of peri-traumatic stress and disruption distress in predicting symptoms of major depression following exposure to a natural disaster. Australian \& New Zealand Journal of Psychiatry, 51(7), 711-718. doi:10.1177/0004867417691852 [PubMed: 28633571]

Berry SD, Ngo L, Samelson EJ, et al. (2010). Competing risk of death: An important consideration in studies of older adults. Journal of the American Geriatrics Society, 58, 783-787. [PubMed: 20345862]

Bleich A, Gelkopf M, Melamed Y, et al. (2006). Mental health and resiliency following 44 months of terrorism: A survey of an Israeli national representative sample. BMC Medicine, 4, 21-21. doi: 10.1186/1741-7015-4-21 [PubMed: 16934160] 
Blumberg SJ, \& Luke JV (2007). Coverage bias in traditional telephone surveys of low-income and young adults. Public Opinion Quarterly, 71, 734-749.

Bonanno GA, Galea S, Bucciarelli A, et al. (2007). What predicts psychological resilience after disaster? The role of demographics, resources, and life stress. Journal of Consulting and Clinical Psychology, 75(5), 671-682. [PubMed: 17907849]

Boscarino JA, Hoffman SN, Adams RE, et al. (2014). Mental health outcomes among vulnerable residents after Hurricane Sandy: Implications for disaster research and planning. Am J Disaster Med, 9(2), 107-120. doi:10.5055/ajdm.2014.0147 [PubMed: 25068940]

Boscarino JA, Hoffman SN, Kirchner HL, et al. (2013). Mental health outcomes at the Jersey Shore after Hurricane Sandy. Int J Emerg Ment Health, 15(3), 147-158. [PubMed: 24558743]

Breslau N, Kessler RC, Chilcoat HD, et al. (1998). Trauma and post-traumatic stress disorder in the community: The 1996 Detroit Area Survey of Trauma. Arch Gen Psychiatry, 55(7), 626-632. [PubMed: 9672053]

Brewin CR, Andrews B, \& Valentine JD (2000). Meta-analysis of risk factors for post-traumatic stress disorder in trauma-exposed adults. Journal of Consulting and Clinical Psychology, 68(5), 748-766. [PubMed: 11068961]

Brilleman SL, Wolfe R, Moreno-Betancur M, et al. (2017). Associations between community-level disaster exposure and individual-level changes in disability and risk of death for older Americans. Soc Sci Med, 173, 118-125. doi:10.1016/j.socscimed.2016.12.007 [PubMed: 27960126]

Brunet A, Weiss DS, Metzler TJ, et al. (2000). An overview of the Peritraumatic Distress Scale. Dialogues in CLinical Neuroscience, 2(1), 44-45. [PubMed: 22034466]

Bryant RA, Waters E, Gibbs L, et al. (2014). Psychological outcomes following the Victorian Black Saturday bushfires. Australian \& New Zealand Journal of Psychiatry, 48(7), 634-643. doi: 10.1177/0004867414534476 [PubMed: 24852323]

Caramanica K, Brackbill RM, Stellman SD, et al. (2015). Post-traumatic stress disorder after Hurricane Sandy among persons exposed to the 9/11 disaster. International Journal of Emergency Mental Health, 17, 356-362. [PubMed: 25960693]

CDC. (2013). Deaths associated with Hurricane Sandy. Retrieved from https://www.cdc.gov/mmwr/ preview/mmwrhtml/mm6220a1.htm

Dowd JB, Palermo T, Chyu L, et al. (2014). Race/ethnic and socioeconomic differences in stress and immune function in The National Longitudinal Study of Adolescent Health. Soc Sci Med, 115, 49-55. doi:10.1016/j.socscimed.2014.06.011 [PubMed: 24946263]

Eltman F (1 8, 2013). After Sandy, many elders opt for assisted living. Philly.com. Retrieved from http://articles.philly.com/2013-01-08/news/36194848_1_retirement-communitylindenhurstcommunity-surge

Fergusson DM, Horwood L, Boden JM, et al. (2014). Impact of a major disaster on the mental health of a well-studied cohort. JAMA Psychiatry, 71(9), 1025-1031. doi:10.1001/jamapsychiatry. 2014.652 [PubMed: 25028897]

Forbes D, Alkemade N, Waters E, et al. (2015). The role of anger and ongoing stressors in mental health following a natural disaster. Australian \& New Zealand Journal of Psychiatry, 49(8), 706713. doi:10.1177/0004867414565478

Galea S, Brewin CR, Gruber M, et al. (2007). Exposure to hurricane-related stressors and mental illness after Hurricane Katrina. Archives of General Psychiatry, 64(12), 1427-1434. [PubMed: 18056551]

Galea S, Nandi A, \& Vlahov D (2005). The epidemiology of post-traumatic stress disorder after disasters. Epidemiologic Reviews, 27, 78-91. [PubMed: 15958429]

Green G, Lowe SR, \& Rhodes JE (2012). What can multiwave studies teach us about disaster research: An analysis of low-income Hurricane Katrina survivors. Journal of Traumatic Stress, 25, 299-306. [PubMed: 22684676]

Gruebner O, Lowe SR, Sampson L, et al. (2015). The geography of post-disaster mental health: Spatial patterning of psychological vulnerability and resilience factors in New York City after Hurricane Sandy. International Journal of Health Geographics, 14(1), 16. doi:10.1186/s12942015-0008-6 [PubMed: 25889102] 
Guha-Sapir D, Hoyois P, \& Below R (2015). Annual disaster statistical review 2014: the numbers and trends. Retrieved from Brussels, Belgium:

Hamama-Raz Y, Palgi Y, Shrira A, et al. (2015). Gender differences in psychological reactions to Hurricane Sandy among New York metropolitan area residents. Psychiatric Quarterly, 86(2), 285296. doi:10.1007/s11126-014-9333-3 [PubMed: 25428781]

Heid AR, Christman Z, Pruchno R, et al. (2016). Vulnerable, but why? Posttraumatic stress symptoms in older adults exposed to Hurricane Sandy. Disaster Medicine and Public Health Preparedness. doi:10.1017/dmp.2016.15

Hobfoll SE (2001). The influence of culture, community, and the nested-self in the stress process: Advancing conservation of resources theory. Applied Psychology, 50(3), 337-421. doi: 10.1111/1464-0597.00062

HRD. (2014). The thirty costliest mainland US tropical cyclones, 1900-2013. Retrieved from http:// www.aoml.noaa.gov/hrd/tcfaq/costliesttable.htm

IDMC. (2012). People displaced by disasters. Retrieved from http://www.internaldisplacement.org/ assets/publications/2013/2012-global-estimates-corporate-en.pdf

Jayawickreme N, Mootoo C, Fountain C, et al. (2017). Post-conflict struggles as networks of problems: A network analysis of trauma, daily stressors and psychological distress among Sri Lankan war survivors. Soc Sci Med, 190, 119-132. doi:10.1016/j.socscimed.2017.08.027 [PubMed: 28858697]

Kessler RC, Galea S, Gruber MJ, et al. (2008). Trends in mental illness and suicidality after Hurricane Katrina. Molecular Psychiatry, 13(4), 374-384. [PubMed: 18180768]

Kessler RC, Sonnega A, Broment E, et al. (1995). Post-traumatic stress disorder in the National Comorbidity Survey. Archives of General Psychiatry, 52(12), 1048-1060. [PubMed: 7492257]

Kim S, Kulkarni PA, Rajan M, et al. (2017). Hurricane Sandy (New Jersey): Mortality rates in the following month and quarter. American Journal of Public Health, 107(8), 1304-1307. doi:10.2105/ ajph.2017.303826 [PubMed: 28640678]

Lieberman-Cribbin W, Liu B, Schneider S, et al. (2017). Self-reported and FEMA flood exposure assessment after Hurricane Sandy: Association with mental health outcomes. PLoS ONE, 12(1), e0170965. doi:10.1371/journal.pone.0170965 [PubMed: 28129410]

Lock S, Rubin GJ, Murray V, et al. (2012). Secondary stressors and extreme events and disasters: a systematic review of primary research from 2010-2011. PLoS Currents, 4, ecurrents.dis.a9b76fed71b72dd75c75bfcfc13c87a72f24f. doi:10.1371/ currents.dis.a9b76fed1b2dd5c5bfcfc13c87a2f24f

Lowe SR, Sampson L, Gruebner O, et al. (2015). Psychological resilience after Hurricane Sandy: The influence of individual- and community-level factors on mental health after a large-scale natural disaster. PLoS ONE, 10(5), e0125761. doi:10.1371/journal.pone.0125761 [PubMed: 25962178]

Lowe SR, Sampson L, Gruebner O, et al. (2016). Community unemployment and disaster-related stressors shape risk for posttraumatic stress in the longer-term aftermath of Hurricane Sandy. Journal of Traumatic Stress, 29(5), 440-447. doi:10.1002/jts.22126 [PubMed: 27696535]

Neria Y, Nandi A, \& Galea S (2008). Post-traumatic stress disorder following disasters: A systematic review. Psychological Medicine, 38, 467-480. [PubMed: 17803838]

Norris FH, Friedman MJ, Watson PJ, et al. (2002). 60,000 Disaster victims speak: Part I. An empirical review of the empirical literature, 1981-2001. Psychiatry, 65(3), 207-239. doi:10.1521/psyc. 65.3.207.20173 [PubMed: 12405079]

Phifer JF, \& Norris FH (1989). Psychological symptoms in older adults following natural disaster: Nature, timing, duration, and course. Journals of Gerontology, 44(6), S207-S217. [PubMed: 2809114]

Picou JS, \& Hudson K (2010). Hurricane Katrina and mental health: a research note on Mississippi Gulf Coast residents. Sociol Inq, 80(3), 513-524. [PubMed: 20827859]

Pietrzak RH, Tracy M, Galea S, et al. (2012). Resilience in the face of disaster: Prevalence and longitudinal course of mental disorders following Hurricane Ike. PLoS ONE, 7(6), e38964. doi: 10.1371/journal.pone.0038964 [PubMed: 22761716] 
Pruchno R, Heid AR, \& Wilson-Genderson M (2016). The Great Recession, Life Events, and Mental Health of Older Adults. The International Journal of Aging and Human Development, 84(3), 294312. doi:10.1177/0091415016671722

Pruchno R, Wilson-Genderson M, Rose M, et al. (2010). Successful aging: Early influences and contemporary characteristics. The Gerontologist, 50(6), 821-833. [PubMed: 20513694]

Rhodes J, Chan C, Paxson C, et al. (2010). The impact of Hurricane Katrina on the mental and physical health of low-income parents in New Orleans. The American Journal of Orthopsychiatry, 80(2), 237-247. doi:10.1111/j.1939-0025.2010.01027.x [PubMed: 20553517]

Schwartz RM, Gillezeau CN, Liu B, et al. (2017). Longitudinal impact of Hurricane Sandy exposure on mental health symptoms. Int J Environ Res Public Health, 14(9). doi:10.3390/ijerph14090957

Schwartz RM, Liu B, Sison C, et al. (2016). Study design and results of a population-based study on perceived stress following Hurricane Sandy. Disaster Med Public Health Prep, 10(3), 325-332. doi:10.1017/dmp.2015.157 [PubMed: 27113715]

Singer JD, \& Willet JB (2003). Applied longitudinal data analysis: Modeling change and event occurrence: Oxford University Press.

Slopen N, Williams DR, Fitzmaurice GM, et al. (2011). Sex, stressful life events, and adult onset depression and alcohol dependence: are men and women equally vulnerable? Soc Sci Med, 73(4), 615-622. doi:10.1016/j.socscimed.2011.06.022 [PubMed: 21782304]

Steinglass P, \& Gerrity E (1990). Natural diasters and post-traumatic stress disorder short-term versus long-term recovery in two disaster-affected communities. Journal of Applied Social Psychology, 20(21), 1746-1765. doi:10.1111/j.1559-1816.1990.tb01509.x

Tang B, Liu X, Liu Y, et al. (2014). A meta-analysis of risk factors for depression in adults and children after natural disasters. BMC Public Health, 14(1), 623. doi:10.1186/1471-2458-14-623 [PubMed: 24941890]

Thompson MP, Norris FH, \& Hanacek B (1993). Age differences in the psychological consequences of Hurricane Hugo. Psychology and Aging, 8(4), 606-616. [PubMed: 8292289]

Tolin DF, \& Foa EB (2006). Sex differences in trauma and post-traumatic stress disorder: A quantitative review of 25 years of research. Psychological Bulletin, 132, 959-992. [PubMed: 17073529]

Tsuboya T, Aida J, Hikichi H, et al. (2016). Predictors of depressive symptoms following the Great East Japan earthquake: A prospective study. Soc Sci Med, 161, 47-54. doi:10.1016/j.socscimed. 2016.05.026 [PubMed: 27239707]

U.S.Department of Commerce. (2013). Service assessment Hurricane/post-tropical Cyclone Sandy, October 22-29, 2012. Retrieved from http://www.nws.noaa.gov/os/assessments/pdfs/Sandy13.pdf

Utzon-Frank N, Breinegaard N, Bertelsen M, et al. (2014). Occurrence of delayed-onset posttraumatic stress disorder: a systematic review and meta-analysis of prospective studies. Scandinavian Journal of Work, Environment \& Health(3), 215-229. doi:10.5271/sjweh.3420 


\section{Research Highlights}

- Tests the effect of geographic exposure on depressive symptoms.

- Tests the effect of peri-traumatic stress on depressive symptoms.

- Tests the effect of personal and property loss on depressive symptoms.

- Tests the effect of post-storm hardship on depressive symptoms.

- $\quad$ Peri-traumatic stress has the strongest effects on depressive symptoms. 


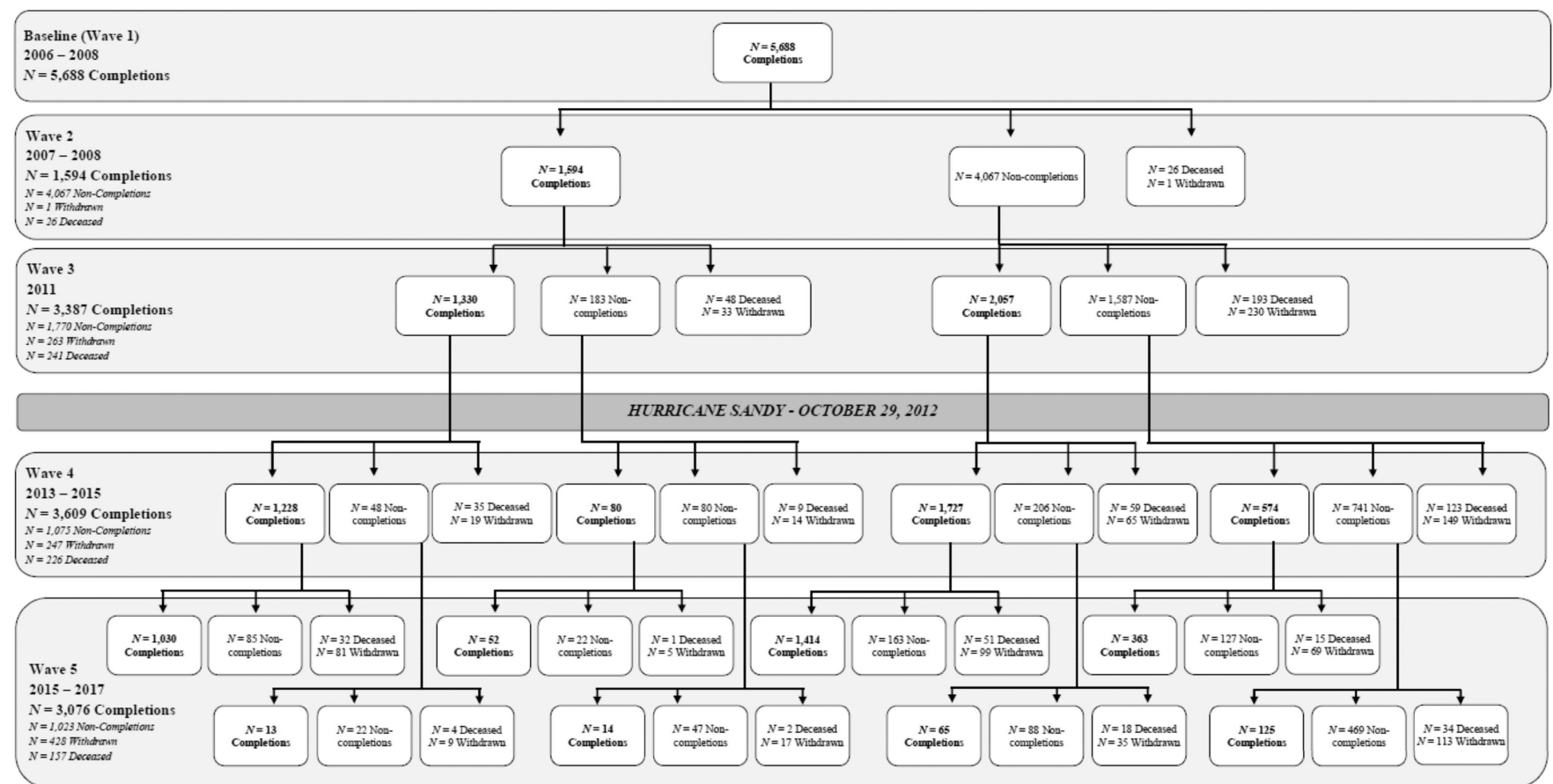

Figure 1.

ORANJ BOWL sample flow across waves, within context of Hurricane Sandy 
Table 1.

Sample descriptive statistics by time.

\begin{tabular}{|c|c|c|c|c|}
\hline Variable & $\begin{array}{c}\text { Wave } 1 \\
N=\mathbf{5 6 8 8}\end{array}$ & $\begin{array}{c}\text { Wave } 3 \\
N=\mathbf{3 3 8 7}\end{array}$ & $\begin{array}{c}\text { Wave } 4 \\
N=3609\end{array}$ & $\begin{array}{c}\text { Wave } 5 \\
N=3076\end{array}$ \\
\hline Age $[M(S D)]$ & $60.7(7.1)$ & $60.8(7.0)$ & $60.5(6.9)$ & $60.2(6.9)$ \\
\hline Sex (Female) & $3621(63.7)$ & $2202(65.0)$ & $2327(64.5)$ & $2956(63.6)$ \\
\hline African American & $646(11.4)$ & $276(8.1)$ & $314(8.7)$ & $222(7.2)$ \\
\hline \multicolumn{5}{|l|}{ Income } \\
\hline Less than $\$ 15 K$ & $365(7.3)$ & $152(5.0)$ & $155(4.81)$ & $106(3.71)$ \\
\hline$\$ 15 K-\$ 30 K$ & $601(12.0)$ & $289(9.5)$ & $297(9.2)$ & $248(8.7)$ \\
\hline$\$ 30 \mathrm{~K}-\$ 50 \mathrm{~K}$ & $862(17.2)$ & $502(16.5)$ & $507(15.7)$ & $445(15.6)$ \\
\hline$\$ 50 \mathrm{~K}-\$ 80 \mathrm{~K}$ & $1133(22.6)$ & $698(23.0)$ & $735(22.8)$ & $661(23.1)$ \\
\hline$\$ 80 \mathrm{~K}-\$ 150 \mathrm{~K}$ & $1291(25.7)$ & $875(28.8)$ & $955(29.6)$ & $876(30.7)$ \\
\hline More than $\$ 150 \mathrm{~K}$ & $770(15.3)$ & $520(17.1)$ & $573(17.8)$ & $520(18.2)$ \\
\hline Missing & $666(11.7)$ & $351(10.4)$ & $382(10.6)$ & $345(10.8)$ \\
\hline \multicolumn{5}{|l|}{ Educational Attainment } \\
\hline Not HS Graduate & $306(5.4)$ & $115(3.4)$ & $114(3.2)$ & $80(2.6)$ \\
\hline HS Graduate or GED & $1607(28.25)$ & $863(25.5)$ & $897(24.9)$ & $701(22.8)$ \\
\hline Some college & $852(15.0)$ & $487(14.4)$ & $515(14.3)$ & $418(13.6)$ \\
\hline 2 yr. college degree & $530(9.3)$ & $320(9.45)$ & $356(9.9)$ & $299(9.7)$ \\
\hline 4 yr. college degree. & $1108(19.5)$ & $697(20.6)$ & $773(21.3)$ & $681(22.1)$ \\
\hline Some post baccalaureate & $220(3.9)$ & $162(4.8)$ & $164(4.55)$ & $150(4.9)$ \\
\hline Masters & $743(13.1)$ & $521(15.4)$ & $562(15.6)$ & $525(17.1)$ \\
\hline \multirow[t]{2}{*}{ Some post-Masters } & $73(1.3)$ & $50(1.5)$ & $52(1.4)$ & $48(1.6)$ \\
\hline & $236(4.15)$ & $168(5.0)$ & $171(4.7)$ & $171(5.6)$ \\
\hline \multicolumn{5}{|l|}{ Doctorate } \\
\hline Missing & $13(0.23)$ & $4(0.12)$ & $5(0.14)$ & $3(0.10)$ \\
\hline Diagnosed Depression $[M(s d)]$ & $1,357(23.9)$ & $746(22.0)$ & $783(21.7)$ & $718(22.5)$ \\
\hline CES-D & $5.76(5.6)$ & $7.21(5.5)$ & $6.06(5.4)$ & $5.5(5.0)$ \\
\hline \multicolumn{5}{|l|}{ Storm Exposure } \\
\hline \multirow[t]{2}{*}{ Peri-traumatic Stressors } & --- & --- & $0.86(1.0)$ & --- \\
\hline & --- & --- & $0.56(1.0)$ & --- \\
\hline \multicolumn{5}{|l|}{ Personal and Property Loss } \\
\hline Post-storm Hardship & --- & --- & $0.13(0.37)$ & --- \\
\hline
\end{tabular}


Table 2.

Bivariate correlations among exposure variables.

\begin{tabular}{lccc}
\hline Variable & Peri-traumatic Stress & Personal and Property Loss & Post-storm Hardship \\
\hline Peri-traumatic Stress & 1 & $0.30^{* * *}$ & $0.14^{* * * *}$ \\
Personal and Property Loss & $0.26^{* * *}$ & 1 & $0.33^{* * *}$ \\
Post-storm Hardship & $0.14^{* * *}$ & $0.29^{* * *}$ & 1 \\
\hline
\end{tabular}

Note: Values above the diagonal pertain to people living in a county designated by FEMA as affected by Hurricane Sandy; values below the diagonal refer to people not living in a FEMA designated county.

**** $p<.001$. 


\section{옴 \\ 길 \\ क \\ 음.}

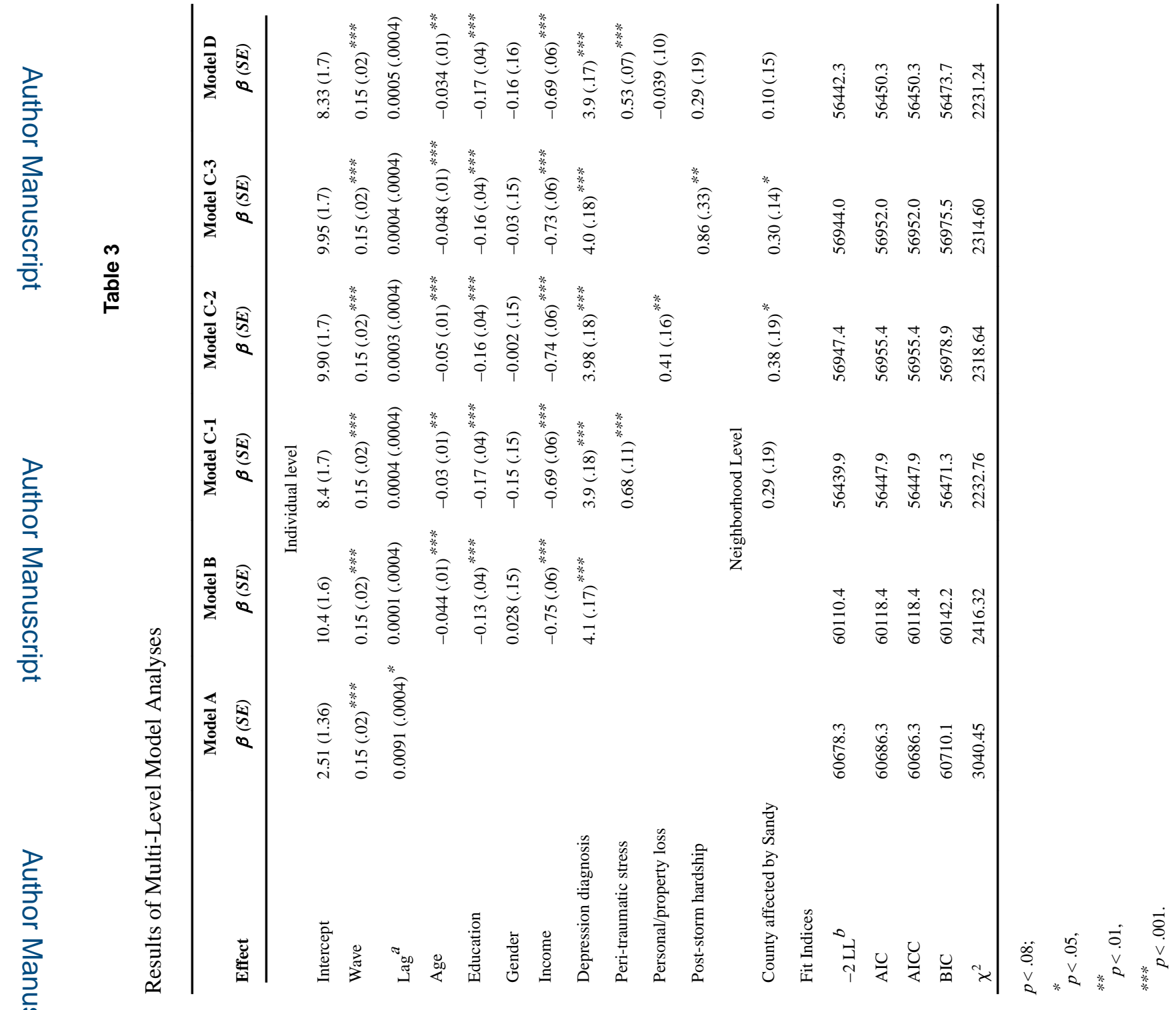

Soc Sci Med. Author manuscript; available in PMC 2020 February 05. 


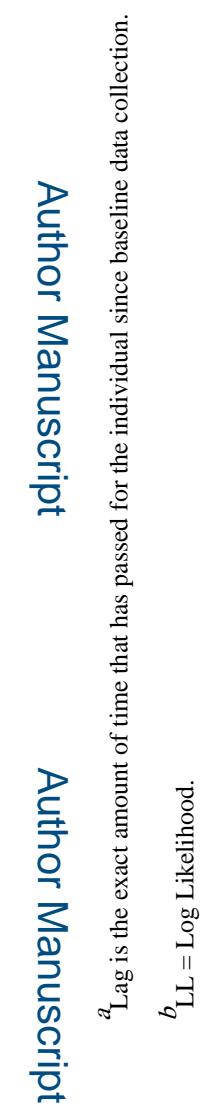

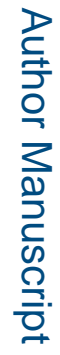

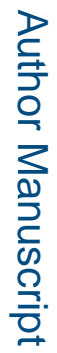

Soc Sci Med. Author manuscript; available in PMC 2020 February 05. 